\title{
E.R. Laws Jr, J.P. Sheehan (eds): Pituitary surgery-a modern approach
}

\author{
Karger, 2006. Hard cover, 286 pp (ISBN: 978-3-211-8055-8051-7) CHF 218.00, EUR \\ 155.50, USD 218.00
}

Michael Powell

Published online: 1 August 2009

(C) Springer-Verlag 2009

This volume is part of a larger, mainly endocrine, series of textbooks. It sets out to overview the developments in pituitary surgery that are currently in use. However, it is, in effect, very much a snapshot in time of pituitary surgery in 2006 at the University of Virginia, where Dr. Laws was then practicing and Dr. Sheehan remains.

Of the chapters, there are only three which are sourced outside that setting, and even then, Dr. Martens, who contributed the interesting chapter on the development of pituitary surgery, a very helpful overview, was only recently a fellow with Dr. Laws in Charlottesville.

The chapters cover a number of aspects, both surgical and peripheral to surgery directly but involved in the practice, such as anaesthesia. The most noteworthy include 'extended surgery', 'surgery in the cavernous sinus', 'histopathology', 'Gamma Knife radiosurgery' and 'managing complications'.

Any collection from this group has to be considered seriously as the senior author is, and has been from some time, one of the most prolific authors and significant contributors in the field. However, the fact remains that endoscopy, surely the biggest development of recent years, is only mentioned in passing. The subject deserves a bigger contribution than the chapter from Georgio Frank of Bologna, whose fascinating overview on endoscopic surgery in the cavernous sinus (which even includes some endocrine results) gives a glimpse of the possibilities of surgery for endocrine functioning tumours in this challenging area. In fact since the publication of this book, the University of Virginia group have embraced pituitary endoscopy wholeheartedly and most of their practice uses this method. Hence, there is already an important gap in what is offered.

What is there is very worthy, particularly in the results of radiosurgery which I have found particularly useful. But a book like this does run the risk of repetition and requires rigorous editing, which I feel was lacking to a certain extent. There are also some areas where I know the Virginia practice excels, particularly in perioperative endocrine management, which I feel is not covered in the depth it deserves.

So in conclusion, a book worth having as it includes well presented and important information which a pituitary surgeon should have at his or her fingertips. It is now slightly out of date and has some gaps.
M. Powell $(\square)$

National Hospital,

Queen Sq,

London WC1N 3BG, England

e-mail: michael.powell@uclh.nhs.uk 